\title{
THE USE OF ANABOLIC STEROIDS IN TOP SWEDISH ATHLETES
}

\author{
Professor A. LJUNGQVIST \\ Karolinska Institutet, Stockholm. President, Swedish Amateur Athletic Association \\ Sofiatornet, Stadion, 11433 STOCKHOLM, Sweden
}

\begin{abstract}
A questionnaire was distributed to the ten best male athletes in each track and field event in Sweden in the year of 1973. In total, 144 athletes were involved in this investigation and answers were received from 99 (69\%). It was asked in the questionnaire whether the athletes had been using any anabolic steroids. In case steroids had been used the athletes were asked to answer specific questions related to positive and negative effects during and after steroid treatment.
\end{abstract}

It was found that $31 \%$ of the athletes who had answered the questionnaire had been using steroids with the aim of improving their competitive results. The use was unevenly distributed between the various types of events. Thus not one single middle or long distance runner had been using steroids compared with $75 \%$ of the throwers. In $61 \%$ the athletes had improved their competition results during or after the use of anabolic steroids, whereas in $39 \%$ no such improvement was recorded. In a certain number even a decrease in competition performance was experienced. $97 \%$ of those who had improved their competition results believed that this improvement was due to the use of anabolic steroids, either alone or as an additional effect to an increased amount of training. In fact $74 \%$ of all athletes who had improved their competition results during anabolic steroid treatment had also deliberately trained harder. It should be noted that no less than $33 \%$ of those athletes who had not experienced any improved competition results in spite of the use of anabolic steroids had also been deliberately training harder.

Side effects were recorded in $74 \%$ of the athletes using anabolic steroids. The most frequent was an increase in body-weight. Most of these athletes also had experienced an increased appetite and an increased muscle mass. Mental disorders of slight degree were reported by a number of athletes. Some of these said they had become more aggressive and active, others reacted the opposite way. In only a limited number of athletes had blood chemistry examinations been performed and in some of these an elevation of serum cholesterol and GOT and GPT were recorded. No jaundice was reported.

It is concluded that the use of anabolic steroids appears to be rather widespread amongst top athletes, particularly throwers. Any effect on the competition results appears to be very questionable since in most of the athletes who had improved their results a period of harder training had also been present. In addition a significant number of athletes who had both been using anabolic steroids and training harder had not improved their results. Certain side effects may appear as a consequence of the use of anabolic steroids. The present investigation has only recorded short term side effects and so far these have been of no medical importance. 